Document downloaded from:

http://hdl.handle.net/10251/60529

This paper must be cited as:

Borrell Tomás, MA.; Salvador Moya, MD.; Miranda, M.; Peñaranda Foix, FL.; Catalá Civera, JM. (2014). Microwave Technique: A Powerful Tool for Sintering Ceramic Materials. Current Nanoscience. 10(1):32-35. doi:10.2174/1573413709666131111225053.

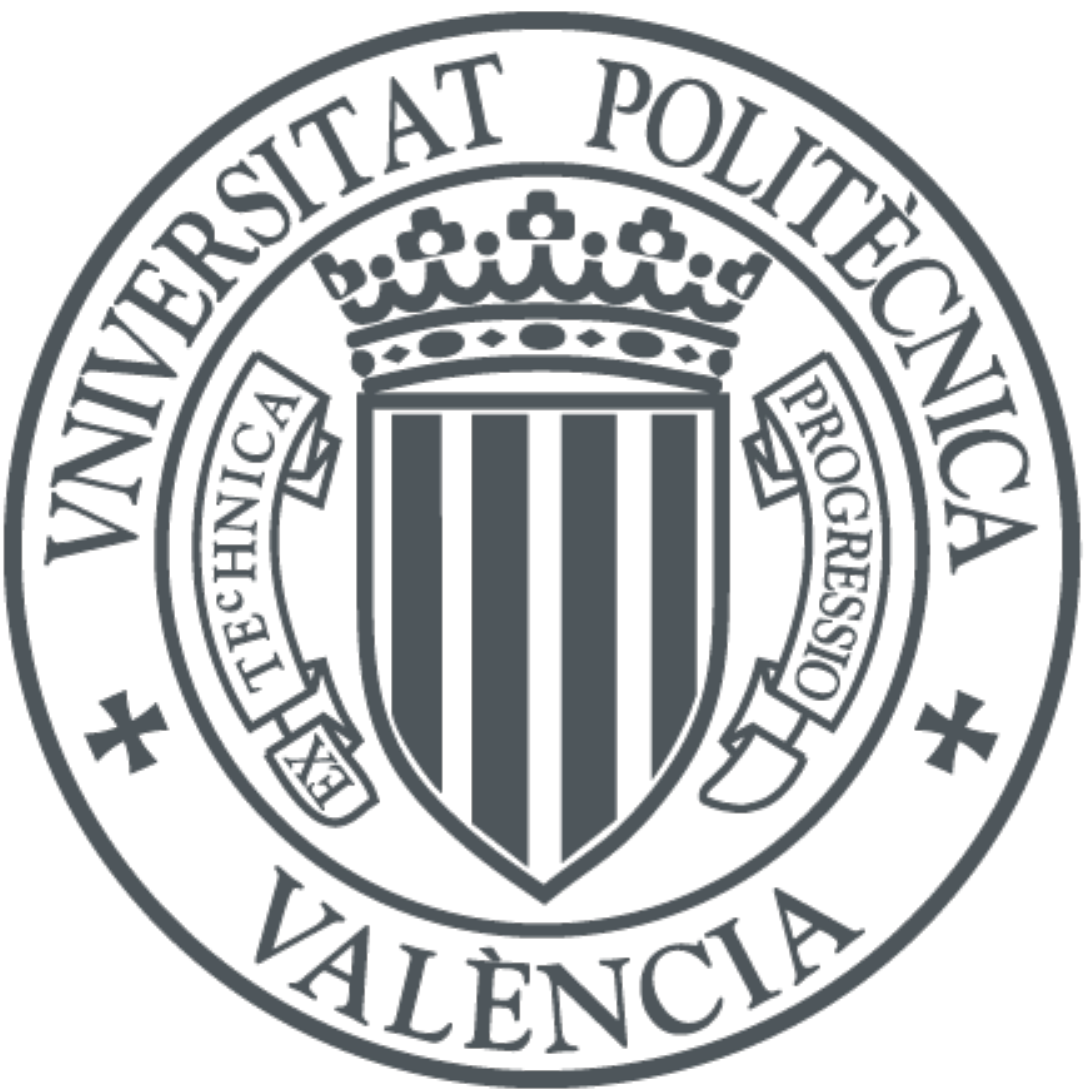

The final publication is available at

http://dx.doi.org/10.2174/1573413709666131111225053

Copyright Bentham Science Publishers

Additional Information 


\title{
MICROWAVE TECHNIQUE: A POWERFUL TOOL FOR SINTERING CERAMIC MATERIALS
}

\section{A. Borrell ${ }^{*}$, M. D. Salvador ${ }^{1}$, M. Miranda ${ }^{2}$, F. L. Penaranda-Foix ${ }^{3}$, J. M. Catala-Civera ${ }^{3}$}

${ }^{1}$ Instituto de Tecnología de Materiales (ITM), Universitat Politècnica de València, Camino de Vera s/n, 46022 Valencia, Spain

${ }^{2}$ Centre for Advanced Structural Ceramics, Department of Materials, Imperial College London, London, UK

${ }^{3}$ Instituto de Aplicaciones de las Tecnologías de la Información y de las Comunicaciones Avanzadas (ITACA), Universitat Politècnica de València, Camino de Vera s/n, 46022 Valencia, Spain

*Corresponding author: aborrell@upvnet.upv.es

\begin{abstract}
Microwave sintering has emerged in recent years as a promising technology for faster, cheaper and eco-friendlier processing of a wide variety of materials, which are regarded as significant advantages against conventional sintering procedures. The present investigation describes a technique for sintering two different ceramic materials by microwave heating: alumina-15vol.\% zirconia and hydroxyapatite nanopowders. The results show that microwave sintering achieves higher density values, excellent mechanical properties and a homogeneous microstructure at lower sintering temperatures. The densities of microwave processed samples were close to the theoretical densities, and the near-netshape of the green body was preserved without significant dimensional changes. The main advantages of microwave heating can be summarized as follows: a more flexible process, reduced processing times and production costs, and environmental benefits. Thus, microwaves are a clear alternative to conventional heating methods, using up to $70 \%$ less energy throughout the whole sintering process.
\end{abstract}

Keywords: Microwave sintering; Grain size; Microstructure; Mechanical properties; Ceramics; Biomaterials

\section{INTRODUCTION}

The application of microwave energy to the processing of various materials such as ceramics, metals and composites offers several advantages over conventional heating methods. These advantages include a unique microstructure and properties, improved product yield, energy savings, reduction in manufacturing cost and synthesis of new materials [1]. Microwave heating is fundamentally different from conventional heating in the way thermal energy is delivered to the 
surface of the material, which, in conventional sintering, is done by means of radiant and/or convection heating and then transferred to the bulk of the material via conduction, and also, from a non-conventional sintering technique known as spark plasma sintering (SPS), where it is possible to consolidate powder compacts by applying an on-off DC electric pulse [2]. In contrast, microwave energy is delivered directly to the material through molecular interaction with an electromagnetic field. Microwave heating is more efficient than conventional methods in terms of the energy used, produces higher temperature homogeneity and is considerably faster than conventional heat sources.

It is well-known that $\mathrm{Al}_{2} \mathrm{O}_{3}-\mathrm{ZrO}_{2}$ composites and nanocomposites have better mechanical properties than $\mathrm{Al}_{2} \mathrm{O}_{3}$ and $\mathrm{ZrO}_{2}$ alone because of the dispersion of metastable tetragonal zirconia particles in the alumina matrix, which transform into the stable monoclinic phase under loading [3-5]. The properties of these materials are determined by their microstructures; therefore, in order to control their microstructural development and achieve fine microstructures, the sintering parameters must be optimized. The synthesis of nanomaterials in powders form has been successfully demonstrated for a large number of materials; however, the synthesis of nano-structured materials in bulk form remains largely unachieved. The sintering of nanopowders to full or nearly full density without appreciable grain growth still presents a significant practical challenge.

Calcium phosphate based ceramics are an attractive alternative in the field of bone substitution and fillers. Dense forms of hydroxyapatite (HAP) with good mechanical properties are often used as reparation material in maxillofacial, dental and orthopaedic surgery [6]. The properties of these materials are very sensitive to the method of preparation and sintering conditions.

In this paper, dense, fine-grained $\mathrm{Al}_{2} \mathrm{O}_{3}-15 \mathrm{vol} . \% \mathrm{ZrO}_{2}$ composites of the submicron-nanocomposite type (alumina grain size controlled in submicron level and zirconia in nanoscale) were prepared by microwave processing. Common commercial $\mathrm{Al}_{2} \mathrm{O}_{3}$ and $\mathrm{ZrO}_{2}$ powders were used as raw materials. A mechanical mixing process (which is simple, low cost and suitable for industry) was applied to prepare the composite powder. A rectangular mono-mode cavity has been custom-designed and fabricated $a d-d o c$ for this study. A comparison with conventional sintering is also presented within the results section.

\section{EXPERIMENTS}

\subsection{Microwave system setup}

The microwave setup consists of a microwave source of $1 \mathrm{~kW}$ at $2.45 \mathrm{GHz}$ connected to a mono-mode rectangular cavity (Fig. 1). This resonant cavity is coupled with an iris and its dimensions are optimized for this application. A 
circulator with a water load is located between the cavity and the microwave power source to prevent high power reflections that can damage the source. This measurement system will allow the user to tune or detune the cavity in order to couple more or less power to follow the heating profile previously established.

FIGURE 1. Microwave system setup.

The approach to tune and detune the cavity consists of a sliding short circuit that can be moved electronically, depending on the reflected and consumed power and on the material temperature. The temperature of the samples is measured with a pyrometer (Optris $\mathrm{GmbH}$, Germany) through a circular hole located at the top of the cavity. Control of the heating rate was perfectly maintained at all times and overheating periods were avoided. The dielectric permittivity of the same material may change dramatically when the temperature changes [7]. Normally, when temperature reaches a certain value, the tan $\delta$ of the material can be increased dramatically causing the thermal runaway phenomenon. To ensure that materials can be successfully processed by microwave technology at a low temperature, it is of high importance to add a susceptor like silicon carbide ( $\mathrm{SiC}$ ) that can efficiently absorb microwave radiation at low temperatures and then reach high temperatures.

\subsection{Experimental procedure}

The raw materials used in this study were commercial $\mathrm{Al}_{2} \mathrm{O}_{3}$ (Sumitomo Co., Japan) with a mean particle diameter of $200 \mathrm{~nm}$ and $\mathrm{ZrO}_{2}$ nanopowders (Tosoh Corp., Japan) with an average particle size of 50-60 nm. For this study, Hydroxyapatite (HAP) powder was synthesized in the laboratory following the sol-gel method (see [8] for details). Green samples were prepared by uniaxial pressing at $200 \mathrm{MPa}$ of pressure in a cylindrical steel die $(2.5 \mathrm{~mm}$ thick, 10 $\mathrm{mm} \phi)$. The samples were sintered by hybrid microwave heating in air, assisted by SiC susceptor. All samples sintered by microwave heating (MW) using a heating rate of $100{ }^{\circ} \mathrm{C} / \mathrm{min}$ and samples sintered by conventional sintering (CS) underwent heating at a rate of $5^{\circ} \mathrm{C} / \mathrm{min}[9]$.

$\mathrm{Al}_{2} \mathrm{O}_{3}-15$ vol. $\% \mathrm{ZrO}_{2}$ samples were sintered by $\mathrm{MW}$ radiation at 1200,1300 and $1400{ }^{\circ} \mathrm{C}$ with a 1 min holding time at the maximum temperature. Conventional sintering of $\mathrm{Al}_{2} \mathrm{O}_{3}-15 \mathrm{vol} . \% \mathrm{ZrO}_{2}$ samples was carried out at 1300 and $1400{ }^{\circ} \mathrm{C}$ with a $2 \mathrm{~h}$ holding time. HAP samples were sintered by MW radiation at 900 and $1000{ }^{\circ} \mathrm{C}$ for a 15 min holding time. For comparison purposes, CS of HAP green compacts was carried out at 900 and $1000^{\circ} \mathrm{C}$ for $2 \mathrm{~h}$.

The bulk density of the sintered samples was measured by Archimedes' principle. Vickers hardness and fracture toughness assessments were carried out using the indentation method (Buehler, model Micromet 5103) with a conventional diamond-pyramid indenter. Measuring conditions for Vickers hardness, $H_{v}$, consisted on applying a load of $5 \mathrm{~N}$ for $10 \mathrm{~s}$ and following the standard specification ASTM E92-72 and to estimate the indentation fracture 
toughness $K_{I C}$, a load of $306 \mathrm{~N}$ were applied. The microstructure cross-sections have been observed using a field emission scanning electron microscope (FEG-SEM S4800 HITACHI, SCSIE of the University of Valencia, Spain). The grain size of the sintered samples was determined by multiplying the average linear intercept by 1.56 . Powder X-ray diffraction analysis (D8 Advance, BRUKER, Germany) was used to determine the crystalline phases.

\section{RESULTS AND DISCUSSIONS}

\section{1. $\mathrm{Al}_{2} \mathrm{O}_{3}-15$ vol. $\% \mathrm{ZrO}_{2}$ materials}

The final relative density, mechanical properties and average grain size of microwave (MW) and conventionally (CS) fabricated $\mathrm{Al}_{2} \mathrm{O}_{3}-15 \mathrm{vol} . \% \mathrm{ZrO}_{2}$ materials are presented in Table 1 and Table 2, respectively.

Table 1. Relative density, mechanical properties and average grain size of microwave sintered $\mathrm{Al}_{2} \mathrm{O}_{3}-15 \mathrm{vol} . \% \mathrm{ZrO}_{2}$ materials.

\begin{tabular}{|c|c|c|c|c|c|}
\hline \multirow{2}{*}{$\begin{array}{c}\text { Sintering temperature } \\
\left({ }^{\circ} \mathrm{C}\right)\end{array}$} & Density (\%) & Vickers & Fracture & Alumina & Zirconia \\
& & toughness & grain size & grain size \\
$(\mathrm{nm})$ & $\left.(\mathrm{MPa} \mathrm{m})^{1 / 2}\right)$ & $180 \pm 4$ & $98 \pm 5$ \\
\hline 1200 & $92.3 \pm 0.1$ & $9.8 \pm 0.3$ & $4.9 \pm 0.06$ & $247 \pm 5$ & $147 \pm 5$ \\
\hline 1300 & $96.4 \pm 0.1$ & $13.1 \pm 0.4$ & $5.2 \pm 0.08$ & $422 \pm 4$ & $253 \pm 4$ \\
\hline
\end{tabular}

Table 2. Relative density, mechanical properties and average grain size of conventionally sintered $\mathrm{Al}_{2} \mathrm{O}_{3}-15 \mathrm{vol} . \% \mathrm{ZrO}_{2}$ materials.

\begin{tabular}{|c|c|c|c|c|c|}
\hline Sintering temperature & \multirow{2}{*}{$\begin{array}{c}\text { Density }(\%) \\
\left({ }^{\circ} \mathrm{C}\right)\end{array}$} & Vickers & Fracture toughness & $\begin{array}{c}\text { Alumina } \\
\text { grain size } \\
\text { grain size } \\
(\mathrm{nm})\end{array}$ \\
\hline 1300 & $92.5 \pm 0.1$ & $6.2 \pm 0.4$ & $5.3 \pm 0.09$ & $254 \pm 6$ & $166 \pm 5$ \\
\hline 1400 & $97.7 \pm 0.1$ & $16.7 \pm 0.3$ & $6.1 \pm 0.08$ & $520 \pm 7$ & $261 \pm 2$ \\
\hline
\end{tabular}

The materials obtained by non-conventional techniques, at the maximum sintering temperature, achieved higher density compared to the samples sintered by CS at the same measured temperature. The combination of rapid heating with low energy applied by the microwave method (eco-friendly process) and the dramatic reduction in cycle time allows densification without the formation of a glass phase. 
During microwave heating, the energy is transferred to the material electro-magnetically and not as a thermal heat flux, enabling the material to be heated at faster rates and shorter sintering times. An effective microwave sintering process should enable the manufacturing of components with controlled structure characteristics and macroscopic shape.

Figure 2 represents the FE-SEM microstructure of $\mathrm{Al}_{2} \mathrm{O}_{3}-15$ vol. $\% \mathrm{ZrO}_{2}$ samples sintered by $\mathrm{MW}$ and $\mathrm{CS}$ methods at 1300 and $1400{ }^{\circ} \mathrm{C}$. Nanocrystalline $\mathrm{Al}_{2} \mathrm{O}_{3}-15$ vol.\% $\mathrm{ZrO}_{2}$ ceramics with fine average grain sizes and a complete elimination of residual porosity were obtained at $1300{ }^{\circ} \mathrm{C}$ by $\mathrm{MW}$. The $\mathrm{CS}$ samples revealed a slight grain growth. These microstructures show similar values of grain size, but the MW micrograph (Figure 2a and 2c) shows a more homogeneous microstructure than the CS ones (Figure $2 \mathrm{~b}$ and $2 \mathrm{~d}$ ).

Figure 2. FE-SEM micrographs of $\mathrm{Al}_{2} \mathrm{O}_{3}-15$ vol. $\% \mathrm{ZrO}_{2}$ composites sintered by $\mathrm{MW}$ at $1300^{\circ} \mathrm{C} / 1 \mathrm{~min}(\mathrm{a}), 1400^{\circ} \mathrm{C} / 1 \mathrm{~min}$ (c), and $\mathrm{CS}$ at $1300^{\circ} \mathrm{C} / 2 \mathrm{~h}(\mathrm{~b}), 1400^{\circ} \mathrm{C} / 2 \mathrm{~h}(\mathrm{~d})$.

Therefore, application of a microwave heating method has provided traces of improvement for grain growth suppression and densification compared to the other sintering technique employed.

The hardness values increase with the density data. A maximum hardness was achieved for the MW sample sintered at $1400{ }^{\circ} \mathrm{C}$, which is an excellent value compared to the CS sample sintered at the same temperature with $2 \mathrm{~h}$ of dwelling time. The fracture toughness of MW-sintered specimens decreased slightly with increasing sintering temperature. The CS samples demonstrate fracture toughness values which can usually be expected for MW samples. For CS samples, this behavior can be attributed to the refining of the microstructure, which is a well-known mechanism for enhancing the mechanical properties of ceramics bodies [10].

\subsection{Hydroxyapatite material}

The XRD pattern of the HAP sample sintered by MW at $1000^{\circ} \mathrm{C}$ with a dwelling time of 15 min, shown in Figure 3 , exhibited peaks suggesting that HAP was the prevailing crystalline phase.

Figure 3. XRD pattern of pure HAP bioceramic sintered by $\mathrm{MW}$ at $1000^{\circ} \mathrm{C} / 15 \mathrm{~min}$.

Density and mechanical properties of MW and CS sintered HAP samples as a function of sintering temperature are shown in Table 3. The increase in mechanical properties agrees with the rapid increase of the density of the HAP compacts. 
Table 3. Density and mechanical properties of HAP material sintered by MW and CS.

\begin{tabular}{|c|c|c|c|}
\hline $\begin{array}{c}\text { Sintering temperature } \\
\left({ }^{\circ} \mathrm{C}\right)\end{array}$ & Density $(\%)$ & Vickers hardness $(\mathrm{MPa})$ & $\begin{array}{c}\text { Fracture toughness } \\
\left(\mathrm{MPa} \mathrm{m}^{1 / 2}\right)\end{array}$ \\
\hline MW-900 & $97.2 \pm 0.1$ & $3.5 \pm 0.4$ & $1.36 \pm 0.09$ \\
\hline MW-1000 & $98.5 \pm 0.1$ & $4.3 \pm 0.4$ & $1.15 \pm 0.08$ \\
\hline CS-900 & $95.1 \pm 0.1$ & $2.4 \pm 0.3$ & $0.81 \pm 0.06$ \\
\hline CS-1000 & $96.6 \pm 0.1$ & $3.8 \pm 0.3$ & $0.89 \pm 0.07$ \\
\hline
\end{tabular}

For the MW sintered HAP compacts, a decrease in sintering temperature from $1000{ }^{\circ} \mathrm{C}$ to $900{ }^{\circ} \mathrm{C}$ led to an increase in the fracture toughness from $1.15 \mathrm{MPa} \mathrm{m}^{1 / 2}$ to $1.36 \mathrm{MPa} \mathrm{m}^{1 / 2}$. In general, the values of fracture toughness for HAP samples reported in literature varies between 0.6 to about $1.0 \mathrm{MPa} \mathrm{m}^{1 / 2}[11,12]$. Raynaud et al. [11] measured a fracture toughness of 1.0 MPa m ${ }^{1 / 2}$ for a hot pressed HAP-based bioceramic. Banerjee et al. [12] obtained dense HAP samples using conventional sintering, with fracture toughness values around $0.8 \mathrm{MPa} \mathrm{m}{ }^{1 / 2}$. The increase in fracture toughness due to microwave sintering is generally attributed to better sinterability and less grain growth than conventionalsintering.

The microstructures of the fracture surfaces of the HAP samples obtained by MW and CS at $1000{ }^{\circ} \mathrm{C}$ are presented in Figure 4.

Figure 4. FE-SEM microstructure of HAP samples sintered by MW at $1000^{\circ} \mathrm{C} / 15 \mathrm{~min}$ (a) and CS at $1000^{\circ} \mathrm{C} / 2 \mathrm{~h}(\mathrm{~b})$.

The FE-SEM micrographs show that CS samples were porous and that their microstructures were non-uniform. The grain size increases for CS processing, since the heating rate is lower than the MW heating rate. At $1000{ }^{\circ} \mathrm{C}$, the differences in grain size are very important. These results confirmed that the use of microwaves during the sintering of nano-sized HAP powders had a positive effect on the densification and microstructural characteristics of HAP-based bioceramic due to homogenous microwave energy distribution, which leads to a volumetrically uniform heating.

\section{CONCLUSIONS}

We successfully employed microwave sintering to obtain dense $\mathrm{Al}_{2} \mathrm{O}_{3}-15 \mathrm{vol} . \% \mathrm{ZrO}_{2}$ and $\mathrm{HAP}$ materials within several minutes. Microwave sintering has a number of benefits in terms of microstructural design and mechanical properties. 
As a general summary, the microwave technique is a powerful tool to sinter ceramic materials with enhanced properties. This process has many advantages over conventional methods including: substantial enhancements in the reaction and diffusion kinetics, relatively shorter cycle times, finer microstructures leading to better quality products, substantial energy savings and eco-friendliness, etc. This study will allow us to continue research on sintered materials by the interesting microwave technique.

\section{ACKNOWLEDGEMENTS}

This work has been carried out under a programme that supports research and development at the Polytechnic University of Valencia under multidisciplinary projects PAID2011/059, SP20120621 and SP20120677. A. Borrell acknowledges the Spanish Ministry of Science and Innovation for her JdC contract (JCI-2011-10498). A. Borrell and F.

L. Peñaranda-Foix want to thank the Generalitat Valenciana for the grant obtained in the frame of the Program BEST/2012.

\section{REFERENCES}

[1] Borrell, A.; Salvador, M.D.; Rayón, E; Peñaranda-Foix, F.L. Improvement of microstructural properties of 3Y-TZP materials by conventional and non-conventional sintering techniques. Ceram. Int., 2012, 38, 39-43.

[2] Chang, S-H.; Choi, J-Ch.; Choi, S-W.; Kim, H-S.; Oh, I-H. Evaluation of Ni-YSZ anode fabricated by spark plasma sintering for SOFC application. J. Korean Powder Metall. Inst., 2008, 15, 405-410.

[3] Woo, S-S.; Kim, H-K. Synthesis and characterization of nanoporous zirconia. J. Korean Powder Metall. Inst., 2007, $14,309-314$

[4] Biamino, S.; Fino, P.; Pavese, M.; Badini C. Alumina-zirconia-yttria nanocomposites prepared by solution combustion synthesis. Ceram. Int., 2006, 32, 509-513.

[5] Chung, T-J.; Kim, H-S. Direct observation on the low temperature degradation due to surface treatment in Y-TZP. J. Korean Powder Metall. Inst., 2010, 17, 197-202.

[6] Legeros, R.Z.; Legeros, J.P. In: Dense hydroxyapatite; L.L. Hench, J. Wilson, Ed; An Introduction to Bioceramics, World Scientific: Singapore, 1993, pp. 139-180.

[7] Demirskyi, D.; Agraval, D.; Ragulya, A. Densification kinetics of powdered copper under single-mode and multimode. Mater. Lett., 2010, 64, 1433-1436.

[8] Miranda, M.; Fernández, A.; Saiz, E.; Tomsia, A.P.; Torrecillas, R. Application of new forming and sintering techniques to obtain hydroxyapatite and $\beta$-TCP nanostructured composites. Int. J. Mat. Res., 2010, 101, $117-121$.

[9] Borrell, A.; Salvador, M.D.; Peñaranda-Foix, F.L.; Cátala-Civera J.M. Microwave sintering of zirconia materials: mechanical and microstructural properties. Inter. J. Appl. Ceram. Technol., 2013, 10, 313-320. 
[10] Winnubst, A.J.A.; Keizer, K.; Burggraaf, A.J. Mechanical properties and fracture behaviour of $\mathrm{ZrO}_{2}-\mathrm{Y}_{2} \mathrm{O}_{3}$ ceramics. J. Mater. Sci., 1983, 18, 1958-1966.

[11] Raynaud, S.; Champion, E.; Lafon, J.P.; Bernache-Assollant, D. Calcium phosphate apatites with variable Ca/P atomic ratio III. Mechanical properties and degradation in solution of hot pressed ceramics. Biomaterials, 2002, 23, 1081-1089.

[12] Banerjee, A.; Bandyopadhyay, A.; Bose, S. Hydroxyapatite nanopowders: synthesis, densification and cellmaterials interaction. Mater. Sci. Eng. C., 2007, 27, 729-735. 


\section{Figures:}

Figure 1.

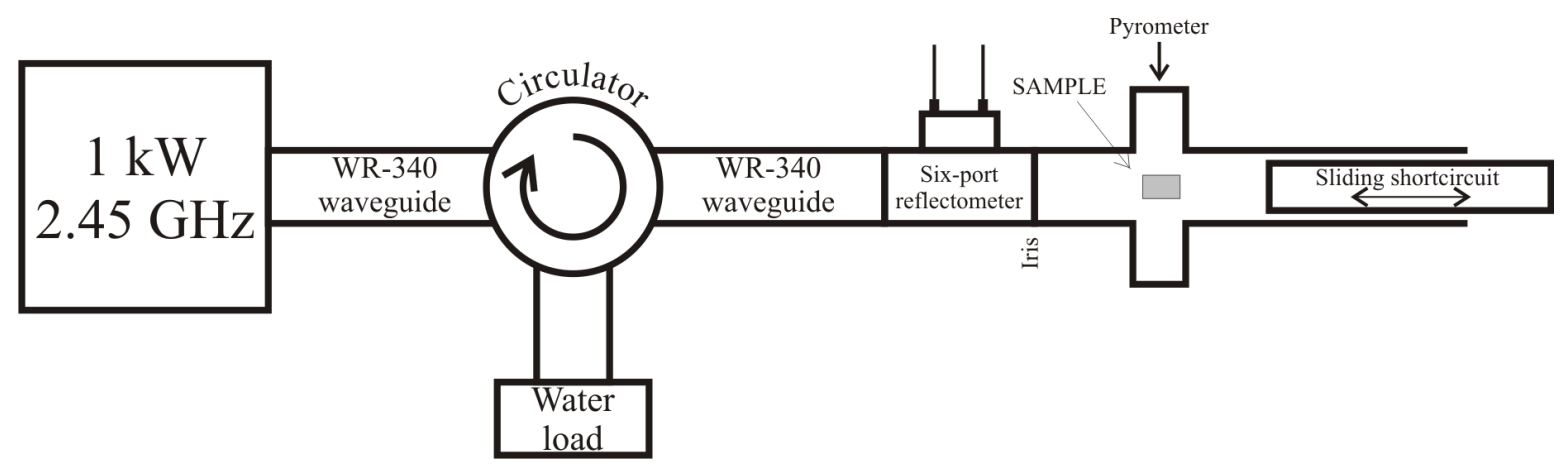

Figure 2.

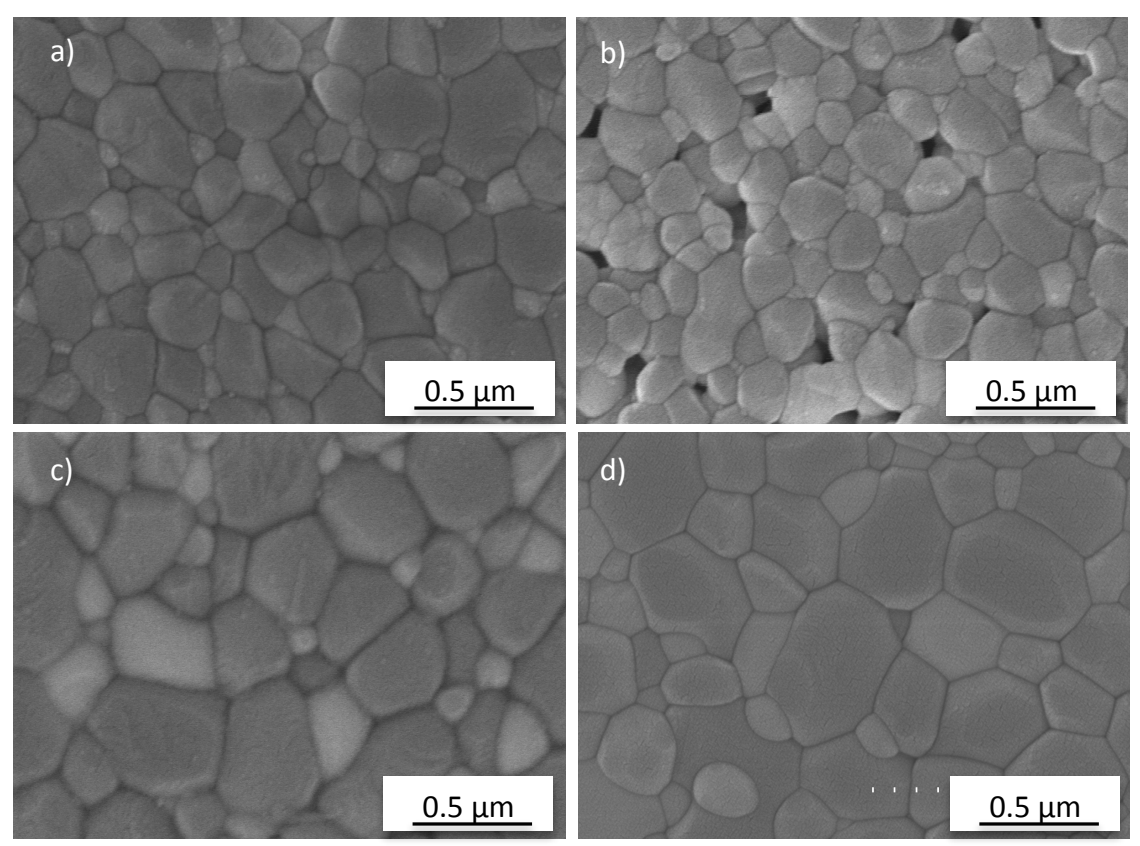


Figure 3.

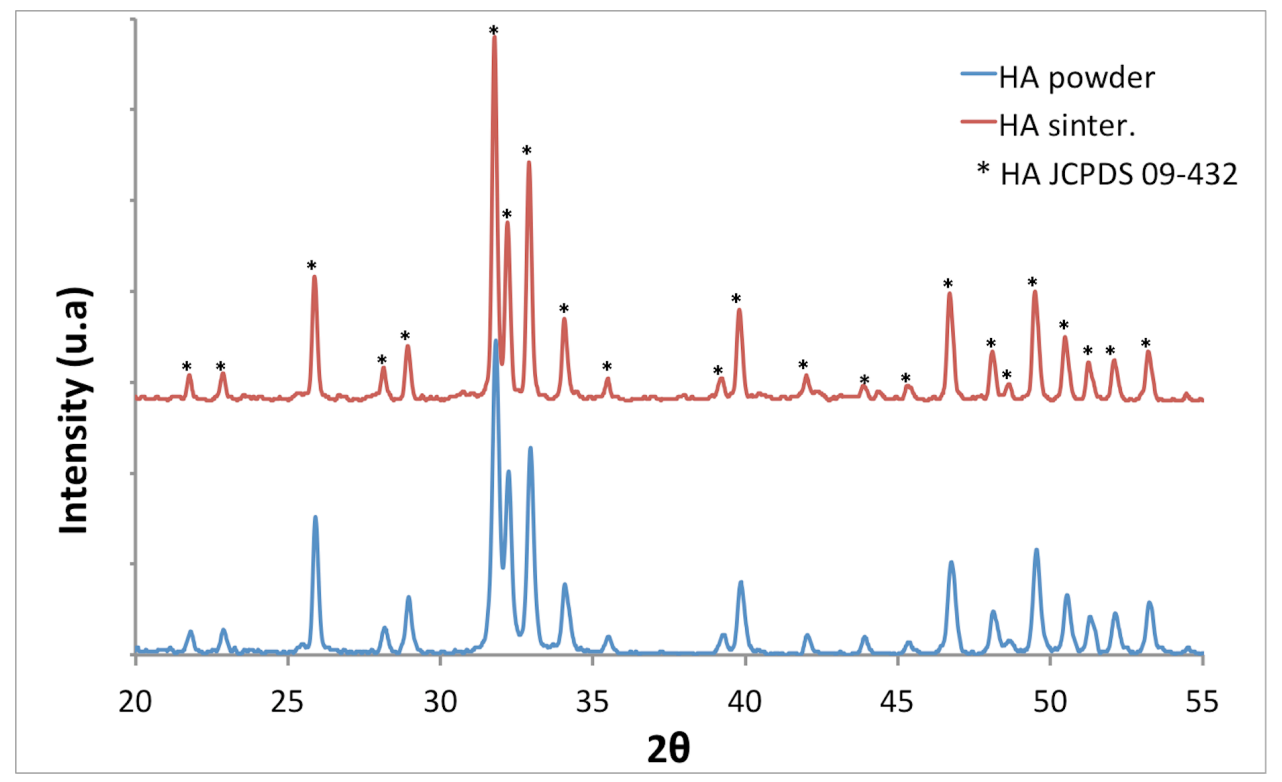

Figure 4.
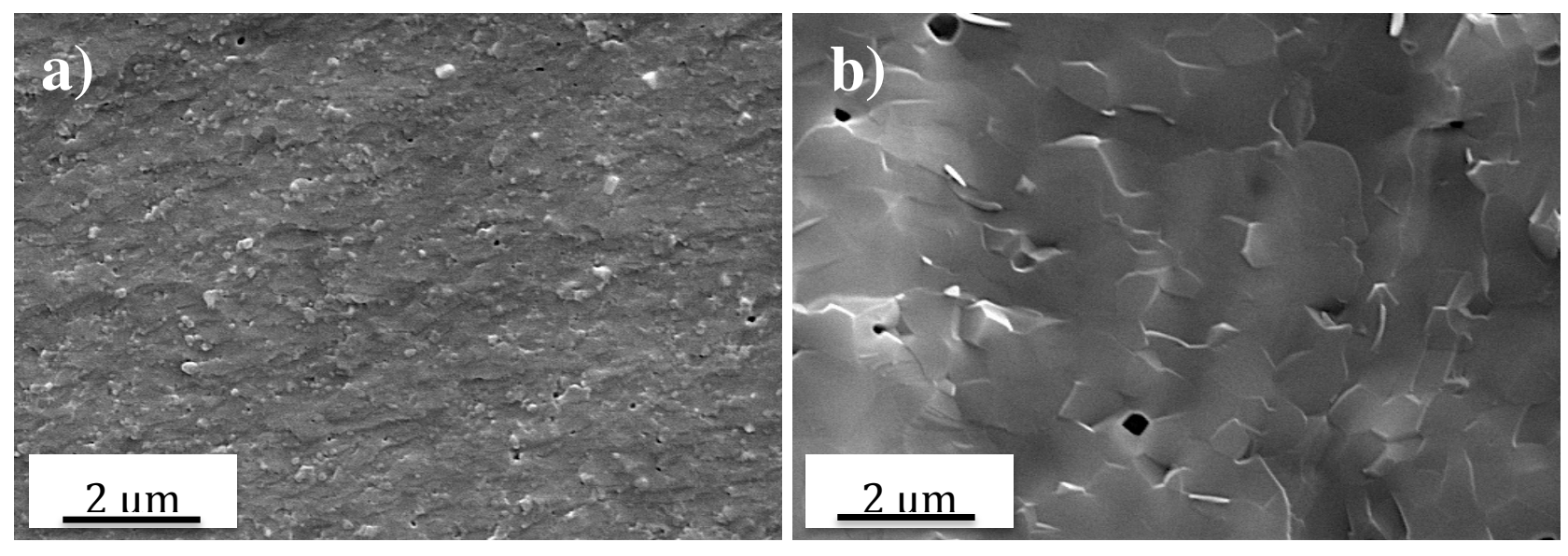